University of Nebraska - Lincoln

DigitalCommons@University of Nebraska - Lincoln

Educational Psychology Papers and

Publications

Educational Psychology, Department of

Spring 2007

\title{
The Social Coping Questionnaire: An Examination of Its Structure with an American Sample of Gifted Adolescents
}

\author{
Kathleen Moritz Rudasill \\ University of Nebraska-Lincoln, kmrudasill@vcu.edu \\ Regan Clark Foust \\ University of Virginia \\ Carolyn M. Callahan \\ University of Virginia, cmc@virginia.edu
}

Follow this and additional works at: https://digitalcommons.unl.edu/edpsychpapers

Part of the Educational Psychology Commons

Rudasill, Kathleen Moritz; Foust, Regan Clark; and Callahan, Carolyn M., "The Social Coping Questionnaire: An Examination of Its Structure with an American Sample of Gifted Adolescents" (2007). Educational Psychology Papers and Publications. 129.

https://digitalcommons.unl.edu/edpsychpapers/129

This Article is brought to you for free and open access by the Educational Psychology, Department of at DigitalCommons@University of Nebraska - Lincoln. It has been accepted for inclusion in Educational Psychology Papers and Publications by an authorized administrator of DigitalCommons@University of Nebraska - Lincoln. 


\title{
The Social Coping Questionnaire: An Examination of Its Structure with an American Sample of Gifted Adolescents
}

\author{
Kathleen Moritz Rudasill, ${ }^{1}$ Regan Clark Foust, ${ }^{2}$ \\ and Carolyn M. Callahan ${ }^{2}$
}

1. University of Louisville

2. Curry School of Education at the University of Virginia

\begin{abstract}
Gifted students report that they are often perceived differently than nonidentified students (Cross, Coleman, \& Stewart, 1993); thus, they employ social coping strategies to manipulate the visibility of their giftedness. The Social Coping Questionnaire (SCQ; Swiatek, 1995) was designed to assess these strategies. This studys purpose was to examine the SCQ's factor structure with a sample of 600 younger (grades 5-7) and older (grades 8-11) gifted boys and girls in the US. and determine the tenability of the factor structure across age and gender groups. Participants' scores were randomly assigned to either exploratory factor analysis (EFA) or confirmatory factor analysis (CFA). Findings from EFA were tested with CFA. Together, these analyses revealed 6 factors. Factor loading patterns from multigroup analyses indicated differences between age and gender groups, and suggested that future investigations of gifted students' social coping strategies include careful examination of the data for factor structure changes that are unique to the sample.
\end{abstract}

Adolescence is a period of development marked by rapid cognitive advancement. It is this progression that allows individuals to understand their world and themselves in more complex and sophisticated ways (Keating, 2004). Inherent in this development is both a heightened sense of self-awareness and a better understanding of what differentiates oneself from significant others. Advanced intellectual ability is one such differentiating factor. 
Gifted students have reported that the visibility of their advanced intellectual ability in some social contexts can be problematic; some believe that when others recognize their giftedness, they are perceived as different and treated as such (Coleman \& Cross, 1988; Cross et al., 1993; Janos, Fung, \& Robinson, 1985; Manaster, Chan, Watt, \& Wiehe, 1994; Manor-Bullock, Look, \& Dixon, 1995; Robinson, 1990). Some gifted adolescents, not necessarily wanting to differ from their peers in intellectual ability or be treated differently because of it, employ a variety of social coping strategies that serve to manipulate the visibility of their giftedness so that they may avoid the "perceived negative social effects of recognized high ability" (Swiatek, 2002, p. 66).

\section{The Social Coping Questionnaire}

In order to measure the specific strategies that gifted adolescents employ, Swiatek (1995) developed the Social Coping Questionnaire (SCQ). The SCQ presents statements that prompt respondents to rate their level of agreement or disagreement related to the thoughts and behaviors of gifted adolescents in dealing with their own giftedness in social situations.

The first iteration of the SCQ (Swiatek, 1995) contained 35 items "that address beliefs and activities relating to various social aspects of intellectual giftedness" (p. 157). It was administered to a sample of 137 students who scored in the top 1\% of students taking the American College Test (ACT) or Scholastic Aptitude Test (SAT). Four social coping strategies emerged from a factor analysis of the scores: Denial of Giftedness, Popularity/Conformity, Peer Acceptance, and Activity Level. Subsequent replications, using increasingly larger and more generalizable samples, split the original factors and uncovered new factors to form a clearer picture of the strategies that gifted students employ to deal with their recognized abilities. For example, Swiatek and Dorr (1998) reported the same four factors and an additional factor that formerly loaded onto the Denial factor: Hiding Giftedness. After adding items to the SCQ and administering it to a sample of 212 Honors and Advanced Placement (AP) participants twice, with 8 weeks in between administrations, Swi- 
atek (2001) found seven factors, three of which had emerged in previous analyses of the SCQ (Denial of Giftedness, Peer Acceptance, and High Activity Level). The new factors were: Using Humor, Conformity, Helping Others, and Emphasis on Popularity. Although the latter sample had many more females than males, these factors explained more variance $(38.5 \%)$ than in previous studies and all had test-retest reliability coefficients above 0.67 .

Finally, Swiatek's (2002) most recent replication used a 34-item SCQ administered to two large samples of younger students (thirdthough sixth-grade summer enrichment program participants) to test the strength of the SCQ factor structure with preadolescents. This replication yielded a six-factor solution almost identical to that found in her previous study (Swiatek, 2001). Compared to all previous replications, these factors explained the most variance in students' responses to items on the SCQ $(40.5 \%)$.

The structure of scores on the SCQ has also been examined using samples of gifted students in Hong Kong (Chan, 2003, 2004, 2005). In an attempt to establish cross-cultural reliability and validity, Chan sampled students who were nominated by their schools to participate in the Chinese University of Hong Kong gifted program because of their intellectual precocity, academic ability, or talent in a specific area. Chan (2003) produced six factors from a factor analysis of a 17item SCQ with adolescents: Denial of Giftedness, Attempting Avoidance, Discounting Popularity, Valuing Peer Acceptance, Prizing Conformity, and Activity Involvement. The same factors emerged from an analysis of a 25-item SCQ with a sample of preadolescent and adolescent students (Chan, 2004).

Chan's (2005) recent replication used a sample of "older" and "younger" students aged 9-19. This time, the same six factors, plus one new factor, Helping Others, emerged. Consistent with Swiatek's (2002) findings, the internal consistency of the younger and older groups' scores was similar, but somewhat lower for the younger sample, possibly because they did not understand some of the questions or they interpreted them differently than the older groups. Furthermore, when the internal consistency values of two scales in Swiatek's (2002) younger sample (Conformity and Denial of Negative Impact of Giftedness) fell below .60, she postulated that maybe certain strategies are just beginning to emerge in younger students and, 
therefore, are not used as consistently or affect student behavior less than with older adolescents. Despite this phenomenon, Chan (2005, p. 23), as did Swiatek (2002), concluded that this measure was "relatively robust and invariant in number and nature across a broad age range from children to adolescence." However, the various applications of the SCQ highlight the inconsistency with which some factors of the SCQ emerged in the various studies (i.e., Hiding Giftedness, Using Humor, and Helping Others), with the different factor structures across studies and with the apparent differences in factor structures across age groups.

In order to better understand the factor structure of the SCQ with Chinese students, Chan (2005) tested the seven factors identified in his study at the construct level using structural equation modeling (SEM). They were all clearly subsumed by one of two higher order constructs, termed Minimizing-Differences Coping and Social-Interaction Coping, with one exception: Discounting Popularity was included under both constructs. The MinimizingDifferences Coping Construct, which encompassed strategies that involved actively attempting to diminish the visibility of giftedness, contained the Denying Giftedness, Attempting Avoidance, Prizing Conformity, and Discounting Popularity factors. The Social-Interaction Coping construct, which subsumed strategies that involved increasing the amount of social interaction, encompassed the Discounting Popularity, Activity Involvement, Helping Others, and Valuing Peer Acceptance factors. Discounting Popularity's inclusion under both constructs suggested that it was interpreted somewhat differently by the older and younger samples. Chan (2005) theorized

that younger students might view discounting the importance of popularity as a way of being more like their peers who might not want to be popular, and to a lesser extent, as a way of promoting social interaction. On the other hand, the older students might view such discounting as a way of distancing themselves from their peers who would prefer to become popular, and largely not as a way of promoting social interaction with peers. (p. 21) 
In sum, six factors consistently emerged from Chan's (2003, 2004, 2005) replications: Denial of Giftedness, Maintaining High (social, extracurricular) Activity Level, Prizing Conformity, Discounting Popularity, Valuing Peer Acceptance, and Attempting Avoidance. Chan (2005) also found an additional factor: Helping Others, which is consistent with Swiatek's (2001) findings. Furthermore, these factors, with the exception of Discounting Popularity, were subsumed under one of two latent constructs: the Minimizing-Differences Coping Construct or the Social-Interaction Coping Construct.

In all, 12 social coping strategies have emerged from factor analyses of scores of the SCQ All factor/strategy names appear just as they were identified originally by the authors of these studies in Table 1. Table 1 also lists the Cronbach's alpha values for the factors that emerged from each analysis of the SCQ

\section{The Current Study}

Only seven studies (Chan, 2003, 2004, 2005; Swiatek, 1995, 2001, 2002; Swiatek \& Dorr, 1998) exist that empirically investigated the SCQ Of those, only three (Chan 2004, 2005; Swiatek 2002) tested its use with younger and older adolescents, one (Swiatek, 2001) established test-retest reliability, and none have examined the ten-ability of the factor structure of the SCQ across gender. The goal of the current study was to employ the SCQ with a sample of gifted preadolescent and adolescent students and answer the following questions: (a) How do the factors identified from the SCQ in our sample compare to those of previous replications, (b) is the factor structure tenable across younger and older adolescents, and (c) is the factor structure tenable across gender? 


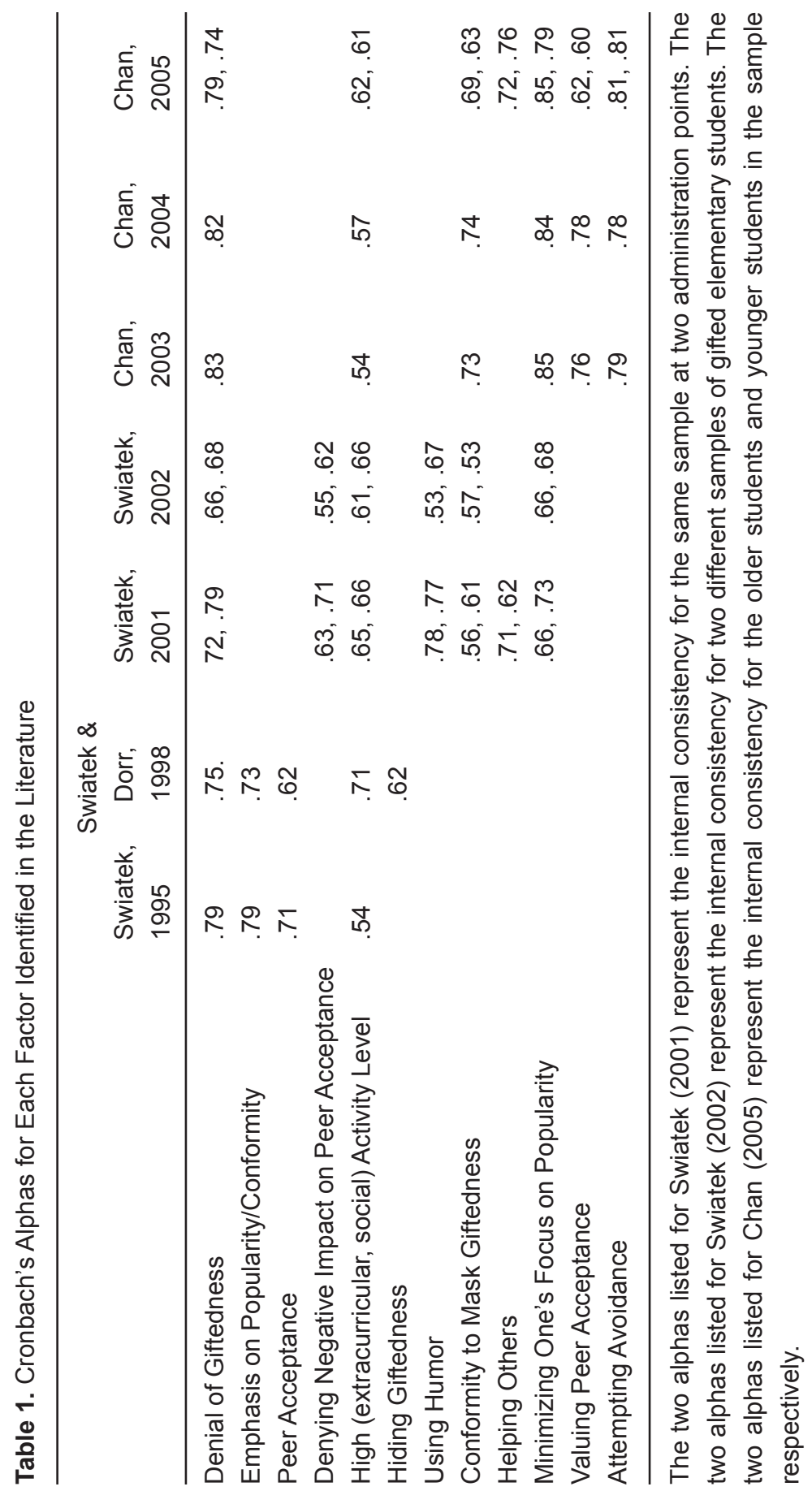




\section{Methods}

\section{Participants}

The sample comprised students participating in a 2-week residential summer enrichment program for gifted students (grades 5-11). Candidates were admitted to the program based on applications that included standardized achievement or IQ test scores, teacher recommendations, and responses to essay questions. Each application was scored by two independent raters using a rubric. In 2004, applications were received from 1,519 students for 936 slots (acceptance rate: $61 \%$ ).

All student participants were recruited by sending letters and consent forms in a packet with other information about the program. Further attempts were made to solicit participation in the study through the use of follow-up mailings and by meeting with parents at registration. Consent forms were collected from parents of 669 students. Of these, 324 younger adolescents (rising into grades 5-7, 188 girls), and 276 older adolescents (rising into grades 8-11, 159 girls), completed the measure used in this study $(N=600)$. Thus, the sample for this study included $64 \%$ of summer session participants. Each student was assigned a code number to ensure confidentiality and to allow for identification of each student's grade and gender.

\section{Design and Procedure}

Early in each camp session (Night 2 or 3), students whose parents had signed consent-to-participate forms convened in small groups (no more than 8 students) with counselors to complete a battery of measures as part of a larger study. One of the measures was the SCQ (Swiatek, 2002). Other measures were a student self-efficacy instrument and the Harter Self-Perception Profile for Children (for rising 5th-7th graders; Harter, 1985) or Adolescents (for rising 8th-11th graders; Harter, 1988). To ensure comfort and confidentiality, students were placed at least 4 feet apart while responding to items. In addition, students only placed their names on consent forms, which were promptly separated from the remaining documents upon re- 
ceipt by researchers. Finally, each participant placed the completed measures into an envelope, sealed it, and returned it to the counselor.

\section{Instruments}

The SCQ (Swiatek, 2002) presents 34 statements that probe the thoughts and behaviors of gifted adolescents dealing with their own giftedness in social situations. Each is accompanied by Likert-style scales prompting respondents to rate their level of agreement or disagreement where $1=$ Strongly True and $7=$ Strongly False. More detailed information on the psychometric properties of the instrument have been previously presented.

\section{Data Analysis}

The entire sample $(N=600)$ of participants who completed consent forms and the SCQ was randomly assigned to one of two subsamples (each $n=300$ ), one for exploratory factor analysis (subsample $\mathrm{E}=$ Exploratory) and the other for confirmatory factor analysis (subsample $\mathrm{C}=$ Confirmatory). Random assignment was conducted using SPSS. Participants with any missing items were deleted listwise.

\section{Exploratory Factor Analysis}

An exploratory factor analysis was conducted with subsample $\mathrm{E}$ to examine the structure of the data collected from the current sample of gifted students. We used principle components analysis with oblique (Promax, $k=4$ ) rotation, owing to the nonorthogonal nature of items on the SCQ The Kaiser-Meyer-Olkin measure of sampling adequacy was .708, which is well above the suggested lower limit of .6 for good factor analysis (Tabachnik \& Fidell, 2001).(FN1)

The choice to use principle components analysis warrants discussion, owing to the controversy within the practice of factor analysis regarding the use of components versus factors for extraction. According to some experts, principal components analysis is an inappropriate method for factor extraction. However, others hold that it 
is a reasonable method. According to Thompson (2004) and Gorsuch (1983), component and factor extraction procedures yield very similar results when the number of variables is larger than 30. Given that the SCQ contains more than 30 items, and we followed the exploratory analysis with confirmatory factor analysis using a different subsample of the data, principal components analysis is appropriate for this study. The initial principal components analysis yielded 10 factors with eigenvalues greater than 1. Examination of the scree plot, however, suggested seven factors. Parallel analysis with random data (see O'Conner, 2000), conducted with 1,000 random data sets and a criteria level of $95 \%$, indicated that no more than seven factors should be retained. This procedure is more restrictive than the traditional eigenvalue threshold criteria, and it is recommended as an additional method for determining how many factors to keep ( $\mathrm{O}^{\prime}$ Conner, 2000). Therefore, principal components analysis was conducted again, this time with seven factors extracted. Pattern matrices were carefully examined. All items with pattern coefficient values less than .5 were dropped, as were all items with pattern coefficient values less than .6 that also loaded on one or more other factors with coefficient values greater than .2. Seven factors comprised the remaining 23 items: Helping Others, Denial of Giftedness, Minimizing the Focus on Popularity, Denying Negative Impact of Giftedness on Peer Acceptance, Conformity to Mask Giftedness, Hiding Giftedness, and Using Humor. The resulting factor structure is shown in Table 2 with both pattern and structure coefficients.

\section{Confirmatory Factor Analysis}

Confirmatory factor analysis was conducted to test this factor structure with subsample $\mathrm{C}$. The fit indices we selected were Comparative Fit Index (CFI) and Goodness of Fit Index (GFI; CFI and GFI values close to 1 indicate very good fit), and Root Mean Square Error of Approximation (RMSEA; values less than .05 indicate good fit). Fit indices indicated adequate fit between the model and the data (CFI = .90$, GFI $=.90$, RMSEA $=.05)$. However, modification indices showed redundancy between items 6 and 13 (both items loaded on the Helping Others factor). Consequently, item 13 was dropped from analysis, 


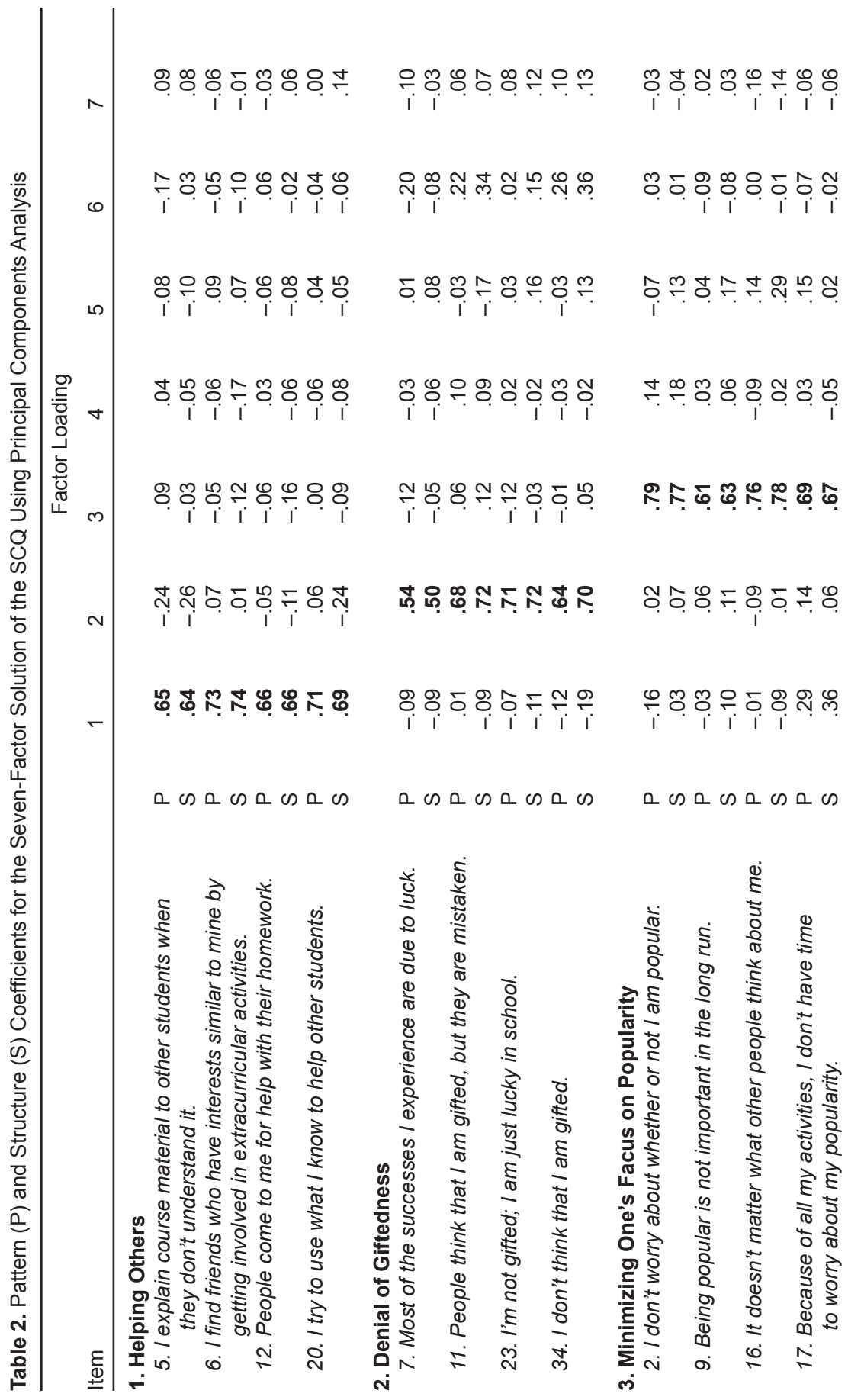




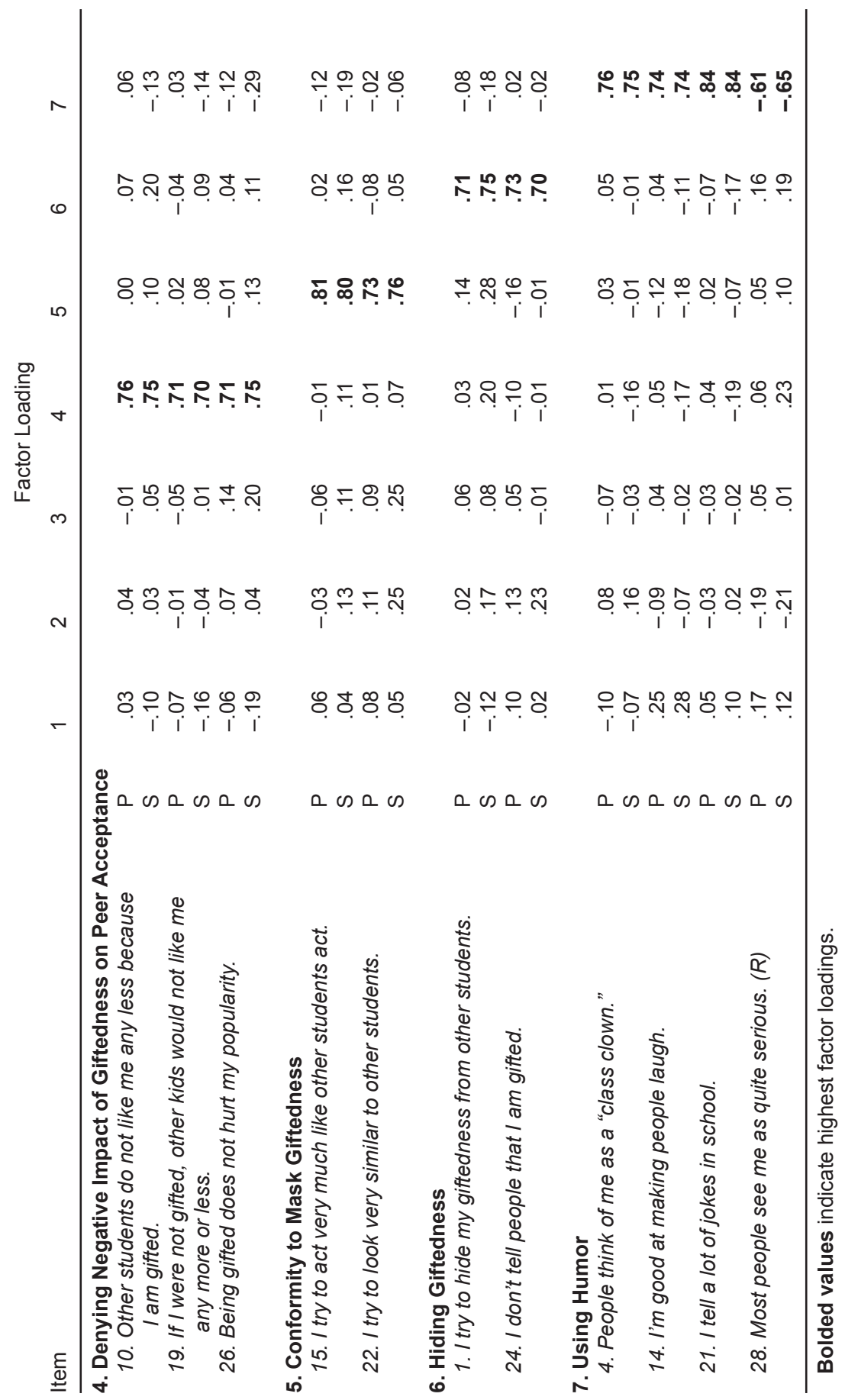


Table 3. Summary of Chi-Square and Fit Indices for Models Tested With Confirmatory Factor Analysis With Subsample C

\begin{tabular}{lcccccc}
\hline & $X^{2}$ & $\Delta X^{2}$ & $d f$ & RMSEA & CFI & GFI \\
\hline Model 1 & 369 & $\mathrm{n} / \mathrm{a}$ & 215 & .05 & .90 & .90 \\
Model 2 & 276 & $93^{* * *}$ & 194 & .04 & .95 & .92 \\
Model 3 & 160 & $116^{* * *}$ & 137 & .02 & .98 & .94 \\
\hline
\end{tabular}

Model 1 = 7 factors, 23 items remaining from exploratory factor analysis with subsample $\mathrm{E}$

Model $2=$ Model 1 with item 13 removed

Model 3 = final full model, Model 2 with Using Humor factor removed

$* * * p<.001$

yielding a better fit between the model and the data (CFI $=.95$, GFI $=$ .92 , RMSEA $=.04)$. Modification indices showed that three of the four items for one factor (Using Humor) loaded onto other factors. Consequently, we removed this factor from subsequent analysis (items 4, 14, 21, and 28), which further improved the model fit (CFI $=.98$, GFI $=.94$, RMSEA $=.02)$. Chi-square and fit indices for all three of these models are summarized in Table 3.

The final model contained the following six factors (with Cronbach's alpha values): Helping Others (.66), Denial of Giftedness (.73), Minimizing One's Focus on Popularity (.72), Denying Negative Impact of Giftedness on Peer Acceptance (.62), Conformity to Mask Giftedness (.74), and Hiding Giftedness (.57). The final model is displayed in Figure 1.

\section{Multigroup Analyses}

To determine the tenability of the factors from the model across different age and gender groups, we conducted two series of multigroup analyses. Specifically, we tested for invariance in the pattern of the factor loadings across groups with the following steps:

1. leaving all factor loadings unconstrained (least restrictive model),

2. constraining all factor loadings (most restrictive model), and

3. removing constraints on each factor's loadings, one factor at a time. 


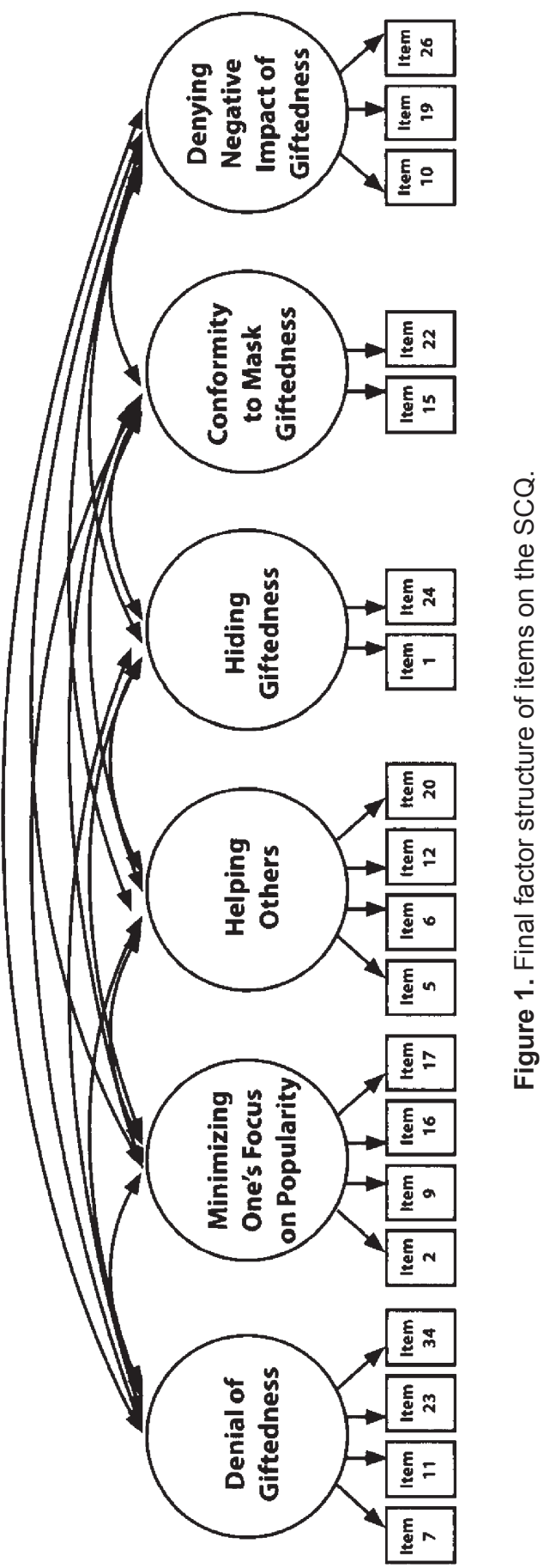


Table 4. Summary of Tests for Invariance across Age Groups of Factor Patterns of the Social Coping Questionnaire

\begin{tabular}{lrrrrrr}
\hline & $X^{2}$ & $\Delta X^{2}$ & $d f$ & RMSEA & CFI & GFI \\
\hline Model 1 & 348 & n/a & 274 & .03 & .93 & .89 \\
Model 2 & 612 & $264^{* * *}$ & 300 & .06 & .71 & .81 \\
Model 3 & 581 & $31^{* * *}$ & 294 & .06 & .74 & .82 \\
Model 4 & 366 & $215^{* * *}$ & 288 & .03 & .93 & .89 \\
Model 5 & 355 & 11 & 282 & .03 & .93 & .89 \\
Model 6 & 354 & 1 & 280 & .03 & .93 & .89 \\
Model 7 & 353 & 1 & 278 & .03 & .93 & .89 \\
\hline
\end{tabular}

Model 1 = no equality constraints on factor loadings between age groups

Model 2 = equality constraints on loadings for all factors

Model 3 = equality constraints on loadings for all factors except for Denial of Giftedness Model 4 = equality constraints on loadings for all factors except Denial of Giftedness and Minimizing

Model 5 = equality constraints on loadings for all factors except Denial of Giftedness, Minimizing, and Helping

Model 6 = equality constraints on loadings for all factors except Denial of Giftedness, Minimizing, Helping, and Hiding

Model 7 = equality constraints only on Denying Negative

*** $p<.001$

Age Groups. Participants were divided into two age groups based on grade: younger adolescents (grades 5-7) and older adolescents (grades 8-11). There was a statistically significant difference between chi-squared values for the least restrictive model (no equality constraints) and the most restrictive model (equality constraints placed on all factor loadings). Removing factor loading constraints one factor at a time revealed the following. When Denial of Giftedness was unconstrained, the chi-square change was statistically significant, and when Minimizing One's Focus on Popularity was also unconstrained, the chi-square change was statistically significant. When constraints were removed from factor loadings for the remaining factors, the changes in chi-square values were nonsignificant. This suggests that there were differences between younger and older adolescents in the patterns of factor loadings for Denial of Giftedness and Minimizing One's Focus on Popularity. All chi-square values and associated fit statistics are shown in Table 4. 
Table 5. Summary of Tests for Invariance across Gender of Factor Patterns of the Social Coping Questionnaire

\begin{tabular}{lcrrrrr}
\hline & $X^{2}$ & \multicolumn{1}{c}{$\Delta x^{2}$} & $d f$ & RMSEA & CFI & GFI \\
\hline Model 1 & 343 & $\mathrm{n} / \mathrm{a}$ & 274 & .03 & .94 & .89 \\
Model 2 & 636 & $293^{* * *}$ & 300 & .06 & .70 & .80 \\
Model 3 & 590 & $46^{* * *}$ & 294 & .06 & .74 & .82 \\
Model 4 & 363 & $227^{* * *}$ & 288 & .03 & .93 & .89 \\
Model 5 & 351 & 12 & 282 & .03 & .94 & .89 \\
Model 6 & 350 & 1 & 280 & .03 & .94 & .89 \\
Model 7 & 345 & 5 & 278 & .03 & .94 & .89 \\
\hline
\end{tabular}

Model 1 = no equality constraints on factor loadings between gender groups

Model 2 - equality constraints on loadings for all factors

Model 3 = equality constraints on loadings for all factors except for Denial of Giftedness Model 4 = equality constraints on loadings for all factors except Denial of Giftedness and Minimizing

Model 5 = equality constraints on loadings for all factors except Denial of Giftedness, Minimizing, and Helping

Model 6 = equality constraints on loadings for all factors except Denial of Giftedness, Minimizing, Helping, and Hiding

Model 7 = equality constraints only on Denying Negative.

${ }^{* * *} p<.001$

Gender. There was a statistically significant difference between the chi-squared values for the least restrictive model and the most restrictive model. We followed the same procedures that we used to understand age group differences in factor loadings. When Denial of Giftedness was unconstrained, the chi-square change was statistically significant. Also removing constraints from Minimizing One's Focus on Popularity resulted in a statistically significant chi-square change, and, finally, removing constraints from Conformity to Mask Giftedness resulted in a statistically significant chi-square change. When constraints were removed from the remaining factors, the chi-square changes were nonsignificant, suggesting that there were differences between girls and boys in the patterns of factor loadings for Denial of Giftedness, Minimizing One's Focus on Popularity, and Conformity to Mask Giftedness. All chi-square values and associated fit statistics are shown in Table 5. 


\section{Discussion and Implications}

The final model contained the same six factors (Helping Others, Denial of Giftedness, Minimizing One's Focus on Popularity, Denying Negative Impact of Giftedness on Peer Acceptance, Conformity to Mask Giftedness, and Hiding Giftedness) as those that have been identified in prior analyses of SCQscores. Specifically, Swiatek (1995, 2001, 2002; Swiatek \& Dorr, 1998) and Chan (2003, 2004, 2005) found various combinations of social coping factors with American and Chinese students. However, several factors that emerged from their studies did not emerge in this study. These include: Emphasizing Popularity/Conformity, Peer Acceptance, Maintaining High (social, extracurricular) Activity Level, Valuing Peer Acceptance, and Using Humor.

There are some analytic explanations for the differences in factors emerging across studies. One possible explanation is that the factor analysis for the current study employed an oblique rotation technique to account for the fact that coping strategies are related constructs, whereas, in the other studies, factor analysis was conducted with Varimax rotation (a rotation technique that treats data as orthogonal). Another explanation is that decision rules for keeping and eliminating items varied across studies, possibly contributing to some differences in the factors that emerged. As mentioned earlier, in the current study items were eliminated if they showed pattern coefficients lower than .5 or .6 while also loading at .2 or above on another factor. Finally, the names assigned to factors in the various studies suggest that the constructs may overlap. For example, although we did not find a factor called Valuing Peer Acceptance, we did find Denying Negative Impact of Giftedness on Peer Acceptance, which may be the same construct.

Our findings suggest three phenomena regarding the measurement of gifted students' social coping strategies. First, with different samples of gifted students, the underlying factor structure of an instrument such as this may vary. For example, some samples, like the current sample, were pulled from summer enrichment programs, whereas others were obtained from traditional school populations (e.g., students in Advanced Placement classes). Although all samples were similar in that they sampled from high-achieving students, 
the current sample included students who have talents not wholly reflected in standardized test scores. Second, the factors that consistently emerged across studies using the SCQ (i.e., Helping Others, Denial of Giftedness, Minimizing One's Focus on Popularity, Denying Negative Impact of Giftedness on Peer Acceptance, Conformity to Mask Giftedness, and Hiding Giftedness) may be the most relevant for use in future studies of gifted populations. Indeed, the consistency with which these factors have emerged across samples and studies indicates that they represent the coping strategies most likely to be used by gifted students. Finally, the factor structure differences that emerged between age (i.e., younger and older adolescents) and gender groups suggest that the instrument's subscales are not universally salient to gifted students. That is, gifted students should not be treated as a homogenous group when examining the social coping strategies they may employ. Future investigations of gifted students' social coping strategies should include careful examination of the data for factor structure changes that are unique to the sample and the subgroups within it.

\section{References}

Chan, D. W. (2003). Dimensions of emotional intelligence and their relationships with social coping among gifted adolescents in Hong Kong. Journal of Youth and Adolescence, 32, 409-418.

Chan, D. W. (2004). Social coping and psychological distress among Chinese gifted students in Hong Kong. Gifted Child Quarterly, 48, 30-41.

Chan, D. W. (2005). The structure of social coping among Chinese gifted children and youths in Hong Kong. Journal for the Education of the Gifted, 29, 8-29.

Coleman, L. J., \& Cross, T. L. (1988). Is being gifted a social handicap ? Journal for the Education of the Gifted, 11(4), 41-56.

Cross, T. L., Coleman, L. J., \& Stewart, R. A. (1993). The social cognition of gifted adolescents: An exploration of the stigma of giftedness paradigm. Roeper Review, 16, 37-40.

Gorsuch, R. L. (1983). Factor analysis (2nd ed.). Hillsdale, NJ: Erlbaum.

Harter, S. (19 8 5). Manual for the Self-Perception Profile for Children. Denver, CO: University of Denver. 
Harter, S. (1988). Manual for the Self Perception Profile for Adolescents. Denver, CO: University of Denver.

Janos, P. M., Fung, H. C., \& Robinson, N. M. (1985). Self-concept, selfesteem, and peer relations among gifted children who feel different. Gifted Child Quarterly, 29, 78-82.

Keating, D. (2004). Cognitive and brain development. In R. Lerner \& L. Steinberg (Eds.), Handbook of adolescent psychology (2nd ed., pp. 45-84). New York: Wiley.

Manaster, G. J., Chan, J. C., Watt, C., \& Wiehe, J. (1994). Gifted adolescents' attitudes toward their giftedness: A partial replication. Gifted Child Quarterly, 38, 176-178.

Manor-Bullock, R., Look, C., \& Dixon, D. N. (1995). Is giftedness socially stigmatizing? The impact of high achievement on social interactions. Journal for the Education of the Gifted, 18, 319-338.

O'Connor, B. P. (2000). SPSS and SAS programs for determining the number of components using parallel analysis and Velicer's MAP test. Behavior Research Methods, Instrumentation, and Computers, 32, 396-402.

Robinson, A. (1990). Does that describe me? Adolescents' acceptance of the gifted label. Journal for the Education of the Gifted, 13, 245-255.

Swiatek, M. A. (1995). An empirical investigation of the social coping strategies used by gifted adolescents. Gifted Child Quarterly, 39, 154-161.

Swiatek, M. A. (2001). Social coping among gifted high school students and its relationship to self-concept. Journal of Youth and Adolescence, 30, 19-39.

Swiatek, M. A. (2002). Social coping among gifted elementary students. Journal for the Education of the Gifted, 26, 65-86.

Swiatek, M. A., \& Dorr, R. M. (1998). Revision of the Social Coping Questionnaire: Replication and extension of previous findings. Journal of Secondary Gifted Education, 10, 252-259.

Tabachnik, B. G., \& Fidell, L. S. (2001). Using multivariate statistics (4th ed.). Boston: Allyn \& Bacon.

Thompson, B. (2004). Exploratory and confirmatory factor analysis: Understanding concepts and applications. Washington, DC: American Psychological Association. 


\section{Notes}

1. Bartlett's test of sphericity was significant $\left(\chi^{2}=2566.029, \mathrm{p}=.000\right)$. However, because this test is likely to be significant with a large sample size, Tabachnik and Fidell (2001) suggest that this test is necessary only when the ratio of cases to variables is less than 5 to 1 . For the current sample, the ratio approached 10 to 1 . 